\title{
Unusual Arachnoid Cyst of the Quadrigeminal Cistern in an Adult Presenting With Apneic Spells and Normal Pressure Hydrocephalus
} -Case Report-

\author{
Cahide TOPSAKAL, Metin KAPlan, Fatih EROL, \\ Hasan CETIN, and Ibrahim OzERCAN*
}

Departments of Neurosurgery and *Pathology, Firat University, School of Medicine, Elazig, Turkey

\begin{abstract}
A 67-year-old woman was admitted to our clinic with symptoms of normal pressure hydrocephalus, lower cranial nerve pareses, and pyramidal and cerebellar signs associated with respiratory disturbances. Computed tomography (CT) and magnetic resonance imaging revealed a $4.7 \times 5.4 \mathrm{~cm}$ quadrigeminal arachnoid cyst causing severe compression of the tectum and entire brain stem, aqueduct, and cerebellum, associated with moderate dilation of the third and lateral ventricles. Emergency surgery was undertaken due to sudden loss of consciousness and impaired breathing. The cyst was totally removed by midline suboccipital craniotomy in the prone position. Postoperatively, her symptoms improved except for the ataxia and impaired breathing. She was monitored cautiously for over 15 days. CT at discharge on the 18th postoperative day revealed decreased cyst size to $3.9 \times 4.1 \mathrm{~cm}$. Histological examination confirmed the diagnosis of the arachnoid cyst of the quadrigeminal cistern. The patient died of respiratory problems on the 5th day after discharge. Quadrigeminal arachnoid cysts may compress the brain stem and cause severe respiratory disturbances, which can be fatal due to apneic spells. Patients should be monitored continuously in the preoperative and postoperative period until the restoration of autonomous ventilation is achieved.
\end{abstract}

Key words: apneic spells, aqueduct stenosis, arachnoid cyst, hydrocephalus, quadrigeminal cistern

\section{Introduction}

Infratentorial arachnoid cysts cause early symptoms which result in diagnosis at an early stage, unlike supratentorial arachnoid cysts which are usually asymptomatic. ${ }^{6,34)}$ Infratentorial arachnoid cyst may occur in five locations: Midline cerebellum, lateral (or hemispheric) retrocerebellum, cerebellopontine angle, clivus, and quadrigeminal cistern. Retrocerebellar and cerebellopontine angle cysts are decidedly more common. ${ }^{22)}$ Quadrigeminal arachnoid cysts are the third most common infratentorial arachnoid cysts and occur between the collicular plates and the incisural notch of the tentorium. ${ }^{3,33)}$ The symptomatology depends on the extent and severity of the compression on the brain stem, cerebellum, and aqueduct. The present case of quadri-

Received May 10, 2001; Accepted August 29, 2001 geminal cistern arachnoid cyst manifested as apneic spells $^{16,31)}$ due to brain stem compression.

\section{Case Report}

A 67-year-old woman was admitted to our department in December 1998 complaining of intermittent memory disturbances, disorientation, unsteadiness, and urinary incontinence for over 6 months, and swallowing difficulty, weakness of lower limbs, and respiratory irregularities for the last 2 weeks. Neurological examination found neurogenic dysphagia due to 9th and 10th cranial nerve pareses and mild pyramidal tract signs like spastic paraparesis, Achilles clonus, hyperreflexia, as well as cerebellar signs. Her gait was broad based. She suffered remarkable apneic spells both while asleep and awake when inattentive in the sitting position, which required close monitoring of physiological 
status. $\mathrm{O}_{2}$ saturation and arterial $\mathrm{PO}_{2}$ and $\mathrm{PCO}_{2}$ during apneic spells were measured, which revealed respiratory impairment particularly in long-lasting attacks. She was treated with assisted ventilation whenever needed.

Computed tomography (CT) revealed a $4.7 \times$ $5.4 \mathrm{~cm}$ quadrigeminal arachnoid cyst causing moderate dilation of the third and lateral ventricles (Fig. 1). The cyst fluid had a density of 5.6 Hounsfield units consistent with cerebrospinal fluid (CSF). Administration of contrast medium caused no enhancement. Magnetic resonance (MR) imaging with or without gadolinium delineated the cyst causing severe compression to the tectum and entire brain stem, aqueduct, and cerebellum on the $T_{1}$ weighted sagittal images and absence of normal flow void in the aqueduct on both $\mathrm{T}_{1}$ - and $\mathrm{T}_{2}$-weighted axial images (Fig. 2). Dynamic MR imaging was planned to evaluate the communication between the cyst and ventricles and subarachnoid space, but the patient suddenly lost consciousness associated with impaired breathing. Emergency surgery was undertaken.

Midline suboccipital craniotomy in the prone position was performed. The cisterna magna was opened to reveal the bilateral cerebellar lobules and tonsils splayed apart by the cyst with a transparent, thin glossy membrane in the middle, emerging below the inferior part of vermis. The inferior medullary vellum was opened to reveal the dome of the cyst, which had probably assimilated the superior medullary vellum because the cyst was bulging completely into the fourth ventricle, instead of arising upwards
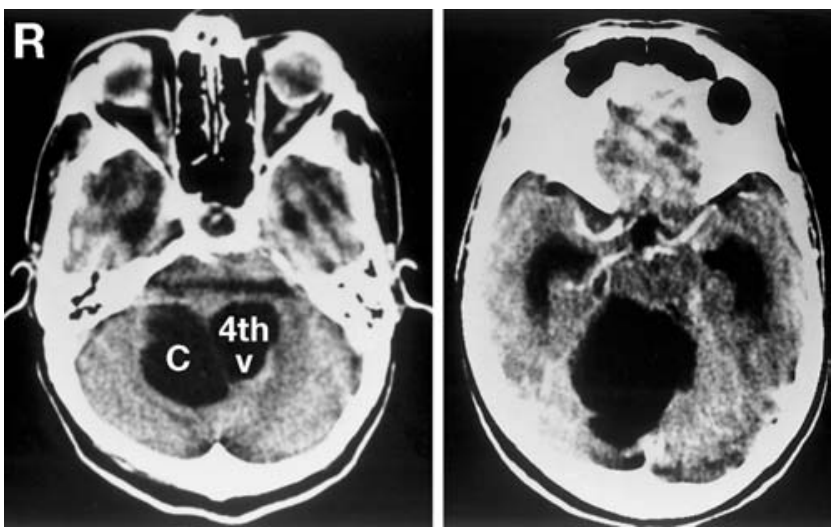

Fig. 1 Computed tomography scans with intravenous contrast medium demonstrating a $4.7 \times 5.4 \mathrm{~cm}$ arachnoid cyst (c) in the quadrigeminal cistern region, with dilation of the fourth ventricle (4th $v$ ) and compression and distortion of the brain stem. by displacing the superior medullary vellum downward and posteriorly. No thinned out cerebellar tissue was found between the two noncommunicating compartments. The cyst was drained of $30 \mathrm{ml}$ fluid which had a protein concentration of $70 \mathrm{mg} / \mathrm{ml}$. The cyst was totally removed with caution from the sides of the fourth ventricle and the last invaginating portion of the cyst was cautiously pulled out from aqueduct. The floor of the fourth ventricle was smooth and shiny.

Postoperatively, her urinary incontinence and disorientation disappeared, except for the ataxia and impaired breathing. She was monitored continuously for over 15 days until the breathing irregularities
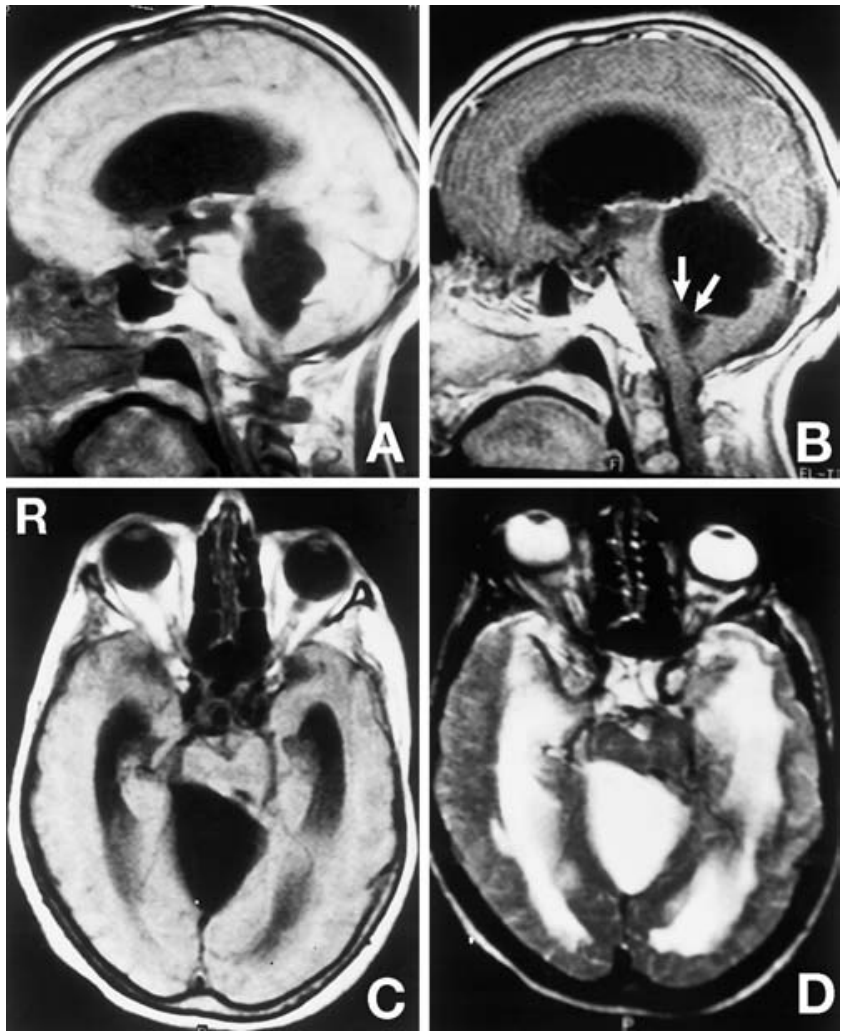

Fig. 2 A, B: Preoperative sagittal $T_{1}$-weighted magnetic resonance (MR) images with gadolinium revealing the cyst abutting the quadrigeminal cistern and causing distortion of the tectum (A), severe compression of the entire brain stem, aqueduct, and cerebellum $(A, B)$, and the septa (arrows) between the fourth ventricle and the cyst (B). Note that the splenium of the corpus callosum is either absent or foreshortened and the tentorium is elevated. C, D: Preoperative axial $\mathrm{T}_{1^{-}}$(C) and $\mathrm{T}_{2}$-weighted (D) $\mathrm{MR}$ images demonstrating the absence of flow void in the aqueduct confirming the obstruction. 
disappeared entirely, which was confirmed by blood gas measurements. Follow-up CT at discharge on the 18th postoperative day revealed the cyst size had decreased to $3.9 \times 4.1 \mathrm{~cm}$ (Fig. 3). Histological examination revealed uni/multi-layered flat mesodermal cells lining a thin collagenous membrane, containing scattered arachnoid remnants. Few blood vessels were present (Fig. 4). Periodic acid-Schiff (PAS) and mucicarmine staining were negative. The diagnosis was arachnoid cyst. She was discharged on the 18th postoperative day but died of aspiration pneumonia one week later.

\section{Discussion}

Paracollicular arachnoid cyst, ${ }^{5,21,25)}$ cyst posterior to the third ventricle, ${ }^{17,21,23)}$ tentorial notch arachnoid cyst, ${ }^{22)}$ cyst of cisterna ambiens, ${ }^{22)}$ paramesencephalic cyst, ${ }^{12)}$ and parapineal cyst ${ }^{12)}$ are all synonyms for quadrigeminal cistern arachnoid cyst. Sixty cases have been reported including ours, ${ }^{14,18,30)}$ but only 16 have been adults $2,4,5,13,14,18,19,22,25,27,33,36)$ (Table 1).

Infratentorial arachnoid cysts are mostly congenital, ${ }^{11,34)}$ although acquired pathologies such as diverticulum from ventricles (due to increased intraventricular pressure), ${ }^{22)}$ inflammation, ${ }^{7,22,37)}$ and trauma $^{7,21,22)}$ are also causative mechanisms. Incarceration of ectopic tissue in form of a secretory organ or choroid plexus may rarely develop from embryonic rests, ${ }^{3,21,22,25,29,35)}$ impeding the free circulation of the fluid. ${ }^{22)}$ The congenital origin ${ }^{6,10)}$ is indicated by the presence of ependymal tissue on the cyst wall and functional failure of outlets of the fourth ventricle accompanied by congenital scoliosis, basilar impression, and syringomyelia, ${ }^{11)}$ and/or aqueductal stenosis, agenesis of corpus callosum, deficient cerebellar lobulation, Chiari 1 malformation, arteriovenous malformation, ${ }^{28)}$ and/or absent septum pellucidum. Infratentorial arachnoid cysts can be intraarachnoid, subarachnoid, or subdural. ${ }^{22)}$ Minor changes in the CSF flow in the early embryonal stages leads to focal splitting of the developing leptomeninges, with the formation of a diverticulum or blind pocket. ${ }^{34)}$ Arachnoid cysts occur at the site of subarachnoid cisterns, so this process is likely to be influenced by the complex folding of the growing encephalon. ${ }^{29)}$

In our case, no traumatic or inflammatory causes were evident and histological examination found no inflammatory or hemorrhagic cells, so the cyst was considered to be of congenital origin. A long duration of symptoms in an adult patient does not exclude a congenital origin. ${ }^{10)}$ Ultrastructural differences between the cyst walls and the normal arachnoid mater support the developmental

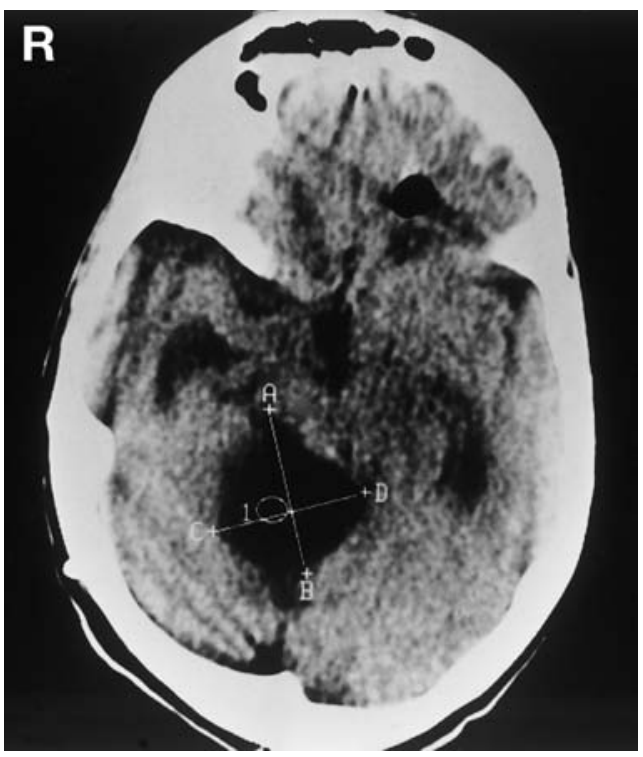

Fig. 3 Postoperative computed tomography scan showing the cyst size has decreased to $4.1 \times$ $3.9 \mathrm{~cm}$. Cyst fluid density was 5.6 Hounsfield units similar to cerebrospinal fluid.

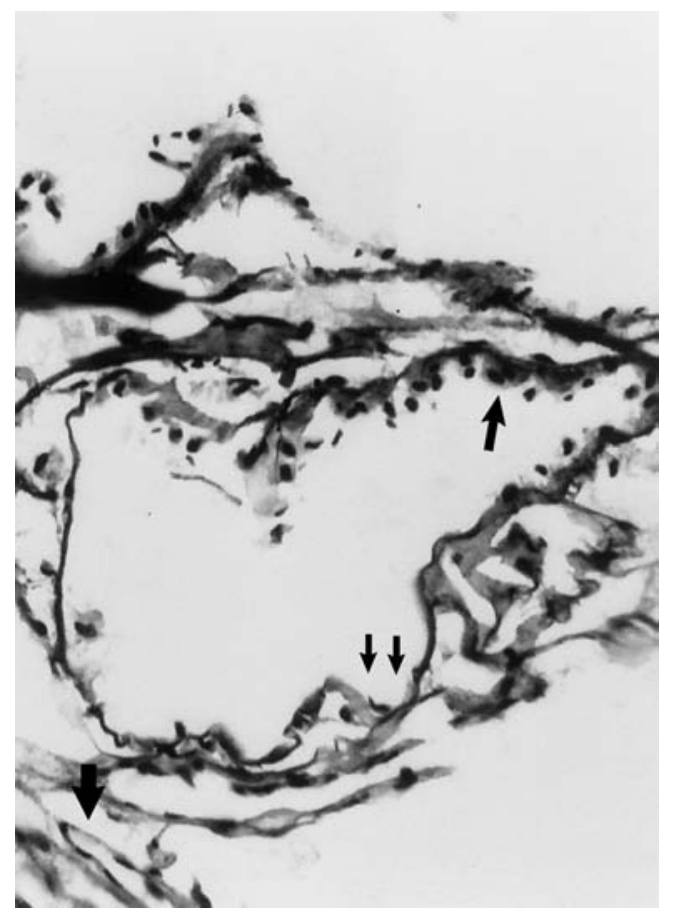

Fig. 4 Photomicrograph of tissue revealing elongated uni/multilayered mesodermal cells lining the collagenous membrane (arrow) and scattered arachnoid cells lining the inner surface of the fine layer of collagen fiber (double arrow). Few blood vessels were found (thick arrow). HE stain, $\times 400$. 
Table 1 Reported cases of quadrigeminal arachnoid cysts in adults

\begin{tabular}{|c|c|c|c|c|c|c|}
\hline $\begin{array}{l}\text { Case } \\
\text { No. }\end{array}$ & Author (Year) & $\begin{array}{l}\text { Age (yrs), } \\
\text { Sex }\end{array}$ & Signs and symptoms & $\begin{array}{l}\text { Associated radiological } \\
\text { findings }\end{array}$ & Operation & Outcome \\
\hline 1 & Katagiri (1960) ${ }^{19)}$ & $37, \mathrm{~F}$ & $\begin{array}{l}\text { HA, vertigo, tinnitus, } \\
\text { deafness, papilledema }\end{array}$ & HS, aqueduct stn & direct attack & died \\
\hline 2 & & $20, \mathrm{M}$ & $\begin{array}{l}\text { HA, vertigo, tinnitus, } \\
\text { ataxia, upw gaze par }\end{array}$ & HS, aqueduct stn & $\begin{array}{l}\text { ventricular } \\
\text { puncture }\end{array}$ & improved \\
\hline 3 & $\begin{array}{l}\text { Odake et al. } \\
(1973)^{25)}\end{array}$ & $15, \mathrm{~F}$ & $\begin{array}{l}\text { increased head size, } \\
\text { papilledema, spasticity }\end{array}$ & HS, aqueduct stn & $\begin{array}{l}\text { direct attack, } \\
\text { cyst exc }\end{array}$ & improved \\
\hline 5 & & $41, \mathrm{~F}$ & NA & NA & NA & remission \\
\hline 6 & $\begin{array}{l}\text { Danziger and } \\
\text { Bloch } \\
(1975)^{5)}\end{array}$ & $19, \mathrm{~F}$ & HA, papilledema & $\begin{array}{l}\text { HS, fourth ventricle, } \\
\text { downward disp }\end{array}$ & direct attack & NA \\
\hline 7 & $\begin{array}{l}\text { Cilluffo et al. } \\
(1983)^{4)}\end{array}$ & $32, \mathrm{M}$ & $\begin{array}{l}\text { HA, blurred vision, } \\
\text { nystagmus }\end{array}$ & HS & VPS & normal \\
\hline 10 & $\begin{array}{l}\text { Wakisaka et al. } \\
(1986)^{36)}\end{array}$ & $35, \mathrm{M}$ & $\begin{array}{l}\text { HA, blurred vision, } \\
\text { papilledema }\end{array}$ & $\begin{array}{l}\text { HS, precentral cerebellar } \\
\text { vein disp }\end{array}$ & $\begin{array}{l}\text { SOC, cyst exc, } \\
\text { VPS }\end{array}$ & normal \\
\hline 11 & $\begin{array}{l}\text { Hanieh et al. } \\
(1988)^{13)}\end{array}$ & $45, \mathrm{M}$ & HA, vomiting & HS & OC, cyst exc & normal \\
\hline 12 & $\begin{array}{l}\text { Pagni et al. } \\
(1990)^{27)}\end{array}$ & $49, \mathrm{~F}$ & $\begin{array}{l}\text { fourth cranial nerve } \\
\text { palsy, diplopia }\end{array}$ & HS & SOC, cyst exc & normal \\
\hline 13 & $\begin{array}{l}\text { Brotchi et al. } \\
(1991)^{2)}\end{array}$ & $41, \mathrm{~F}$ & NA & NA & OC, cyst exc & asymptomatic \\
\hline 14 & & $46, \mathrm{M}$ & NA & pineal region cyst & OC, cyst exc & asymptomatic \\
\hline 15 & $\begin{array}{l}\text { Isaka et al. } \\
(1995)^{18}\end{array}$ & $37, \mathrm{M}$ & HA, imp vision & HS & VPS & NA \\
\hline
\end{tabular}

disp: displacement, exc: excision, HA: headache, hmp: hemiparesis, HS: hydrocephalus, imp: impaired, mem disturb: memory disturbances, NA: not available, SOC: suboccipital craniotomy, stn: stenosis, upw gaze par: upward gaze paralysis, VPS: ventriculoperitoneal shunt.

origin. ${ }^{6,29)}$ Discrimination is difficult when the structure includes both pia mater and ependyma. Microscopic studies of the cyst wall revealed flattened mesothelial cells arranged in single or multiple layers and occasional arachnoid nests lining the inner surface of the fine layer of collagen fiber. ${ }^{20,24)}$ Thin-walled vessels, as in our case, suggest that the arachnoid is not the only membrane involved or that a previous inflammatory reaction may be responsible for neovascularization. ${ }^{22)}$ Negative PAS and mucicarmine staining excluded the presence of epithelial cysts. ${ }^{24)}$

The most common clinical presentation in infants with midline posterior fossa lesions is intracranial hypertension and obstructive hydrocephalus due to the partial or total obstruction of aqueduct ${ }^{5,21)}$ leading to progressive enlargement of the head, without lateralizing signs. ${ }^{3,9)}$ However, the aqueduct stenosis may remain occult in adults, resulting in normal pressure hydrocephalus (NPH). ${ }^{1,20,32)}$ Defective CSF absorption mechanisms ${ }^{6}$ or the blockade of outflow may contribute to NPH as well. ${ }^{10)}$ Long duration, ${ }^{10,22)}$ the episodic course of symptoms, ${ }^{10)}$ and postural influences $^{22,35)}$ are characteristic in adults. Intermittent symptoms may be explained by three different mechanisms: osmotic pressure difference ${ }^{8,15)}$; the presence of the slits in the cyst wall, resulting in a ball valve mechanism ${ }^{8,35)}$; or the presence of secretory ependymal tissue ${ }^{8,11,21,25)}$ which results in increased cyst fluid. The significant difference in protein concentration between the cyst and ventricular CSF seem to support the osmotic theory despite the anatomical communication. Most cysts have a longstanding benign course, but elevated intracranial 
pressure (ICP) and sudden death are known, as in our patient in whom elevated ICP was thought to be the main cause of the neurological deterioration as well as the direct compression of the brain stem. Other symptoms include Parinaud's syndrome, ${ }^{9,15,17}$, 19,33) visual disturbances, ${ }^{4,18,19,21,33,36)}$ nystagmus, ${ }^{4,12,}$ ${ }^{19,21)}$ hearing deficits, ${ }^{19)}$ hemiparesis, ${ }^{33)}$ paraparesis, ${ }^{23)}$ generalized spasticity, ${ }^{7,23,25)}$ clonus, diplopia caused by trochlear nerve, ${ }^{26,27)}$ lateral rectus palsy (due to intracranial hypertension), ${ }^{23)}$ and precocious puberty. ${ }^{9)}$

Our patient presented with memory and gait disturbances, and sphincter incontinence of chronic duration, all consistent with NPH, which was considered to be due to aqueduct stenosis. Postoperatively, her dementia and incontinence improved, and gait ataxia and other cerebellar signs were partially relieved after decompression. Lower cranial nerve symptoms, pyramidal signs, and the occurrence of apneic spells or impaired automatic ventilation confirm the severity of the compression of the brain stem. Impaired automatic ventilation results in essentially normal breathing when the patient is awake but impaired or absent ventilation during sleep or periods of inattention. This condition is known as "Ondine's curse" 31) and can occur in cases of medullary dysfunction, i.e., interruption of the reticulospinal projections connecting the medullary respiratory areas with spinal motor neurons driving the respiratory muscle groups. ${ }^{16)}$ In our patient, the apneic spells could have been fatal during sleep, so she was monitored by measuring arterial $\mathrm{PO}_{2}$ and $\mathrm{PCO}_{2}$ and $\mathrm{O}_{2}$ saturation until this symptom had resolved completely. However, the patient died of aspiration pneumonia at home due to 9th and 10th cranial nerve pareses.

Radionuclide/contrast CT, ventriculography or cisternography ${ }^{3,9,10,15)}$ (if applicable), and cine MR imaging can give information about the communication with the subarachnoid space or CSF dynamics and CSF pulsations. ${ }^{18)}$ Quadrigeminal arachnoid cyst appears as a midline, supracerebellar, infratentorial cyst that abuts the quadrigeminal cistern on CT and MR imaging with no enhancement and the same attenuation values as CSF ${ }^{6}$ ) The enlarging cyst projects downwards and backwards to lie on the superior surface of the cerebellum. ${ }^{14)}$ The aqueduct and fourth ventricles are displaced downwards and forwards and tectal compression occurs. ${ }^{14,15,21,23 \text {, }}$ $26,29,33)$ Generally, the suprapineal recess is elevated and bowed around the cyst, but may extend for a variable distance upward through the tentorial notch, and can be seen on reformatted $\mathrm{CT}^{3)}$ or $\mathrm{MR}$ imaging. The posterior part of the third ventricle is invaded and displaced anteriorly, although not ob- served in our case, and the anterior cerebellar vermis is compressed. ${ }^{5,15,26,30)}$ The aqueduct is stretched and narrowed causing obstructive dilation of the ventricles. ${ }^{33)}$

Carotid angiography may confirm the extent of the hydrocephalus. The perimesencephalic segments of the posterior cerebral artery (PCA) and cisternal segments of the superior cerebellar artery (SCA) are splayed out, and the PCA is displaced upward and the SCA downward. The choroidal loop of the posterior inferior cerebellar artery shows forward and downward displacement. The vein of Galen, the posterior portion of the internal cerebral vein, and the proximal portion of straight sinus show forward and upward displacement, and the precentral cerebellar vein shows posterior displacement. ${ }^{5,15,17,36)}$ If the precentral cerebellar vein bows anteriorly, then an anterior supracerebellar cyst extending to the quadrigeminal region should be considered. ${ }^{36)}$

The most generally accepted treatment is cyst excision, ${ }^{10,22)}$ but opening of the posterior wall of the third ventricle to provide communication between the cyst and the third ventricle, ${ }^{14,15)}$ and other ventricles $^{3,10,30,33,36)}$ may be required to avoid shunt dependency. ${ }^{10,28)}$ Partial removal of the cyst wall and/or external cyst drainage, ${ }^{27,30}$ or internal cyst drainage (windowing) ${ }^{3,10)}$ and/or shunting of ventricles ${ }^{30,33)}$ are options. The cyst wall with the surrounding arachnoid membrane should be removed if cystoperitoneal shunting is not installed. ${ }^{15)}$ Arachnoid cyst of the quadrigeminal cistern usually presents with aqueduct stenosis and requires ventriculoperitoneal (VP) shunting. ${ }^{28)}$ VP shunting preceding craniotomy, and the resection of cyst wall is also recommended by others. ${ }^{9)}$ However, extrathecal diversion of CSF from a lateral ventricle is less advisable as the only or initial procedure due to the risk of further enlargement or upward herniation. ${ }^{3,6,10)}$ We preferred total cyst excision without VP shunting to prevent upward herniation. Monitoring of the patient is necessary for good timing of VP shunting. An attempt to create a window into the collicular plate cistern was abandoned because of multiple layers of thickened arachnoid.3) Neuroendoscopic fenestration is a recent, less-invasive, and apparently effective intervention. ${ }^{14,30}$

Quadrigeminal arachnoid cyst is a rare and treatable pathology in adult patients who present with signs of NPH due to aqueduct stenosis and lateralizing signs caused by direct compression. Preoperatively, attention must be paid to the rare symptom of impaired automatic ventilation, as well as to likely sudden ICP elevations, which may be detrimental while asleep and particularly in the postoperative 
period. Close respiratory monitoring to prevent sudden death is mandatory.

\section{References}

1) Azzimondi G, Calbucci F, Rinaldi R, Vignatelli L, D'Alessandro R: Arachnoid cyst in the region of the fourth ventricle mimicking clinical picture of normal pressure hydrocephalus. Neurosurg Rev 18: 269-271, 1995

2) Brotchi J, Levivier M, Raftopoulos C, Dewitte O, Pirotte B, Noterman J: Three-quarter prone approach to the pineal-tentorial region. Report of seven cases. Acta Neurochir Suppl (Wien) 53: 144-147, 1991

3) Choi SK, Starshak RJ, Meyer GA, Kovnar EH, Sty JR: Arachnoid cyst of the quadrigeminal plate cistern: report of two cases. AJNR Am J Neuroradiol 7: 725-728, 1986

4) Cilluffo JM, Onofrio BM, Miller RH: The diagnosis and surgical treatment of intracranial arachnoid cysts. Acta Neurochir (Wien) 67: 215-229, 1983

5) Danziger J, Bloch S: Paracollicular arachnoid pouches. Am J Roentgenol Radium Ther Nucl Med 124: 310-314, 1975

6) Di Rocco C, Caldarelli M, Di Trapani G: Infratentorial arachnoid cysts in children. Chids Brain 8: 119-133, 1981

7) Dott NM: An introductory review. Presidential address. Dev Med Child Neurol 4: 259-262, 1962

8) Dyck P, Gruskin P: Supratentorial arachnoid cysts in adults. A discussion of two cases from a pathophysiologic and surgical perspective. Arch Neurol 34: 276-279, 1977

9) Fujita K, Sato $\mathrm{H}$, Tamaki $\mathrm{N}$, Matsumoto $\mathrm{S}$ : [Arachnoid cyst of the quadrigeminal cistern]. No Shinkei Geka 12: 1315-1322, 1984 (Jpn, with Eng abstract)

10) Galassi E, Tognetti F, Frank F, Fagioli L, Nasi MT, Gaist G: Infratentorial arachnoid cysts. J Neurosurg 63: 210-217, 1985

11) Gardner WJ, McCormack LJ, Dohn DF: Embryonal atresia of the fourth ventricle: the cause of "arachnoid cyst" of the cerebellopontine angle. J Neurosurg 17: 226-237, 1960

12) Grollmus JM, Wilson CB, Newton TH: Paramesencephalic arachnoid cysts. Neurology 26: 128-134, 1976

13) Hanieh A, Simpson DA, North JB: Arachnoid cysts: a critical review of 41 cases. Childs Nerv Syst 4: 92-96, 1988

14) Hayashi N, Endo S, Tsukamoto E, Hohnoki S, Masuoka T, Takaku A: Endoscopic ventriculocystocisternostomy of a quadrigeminal cistern arachnoid cyst. J Neurosurg 90: 1125-1128, 1999

15) Hayashi T, Kuratomi A, Kuramoto S: Arachnoid cyst of the quadrigeminal cistern. Surg Neurol 14: 267-273, 1980

16) Hodge CJ, Primrose D: Infratentorial procedures: Physiological considerations, in Apuzzo MLJ (ed):
Brain Surgery. Complication Avoidance and Management, vol 2. New York, Churchill Livingstone, 1993, p 1574

17) Huckman MS, Davis DO, Coxe WS: Arachnoid cyst of the quadrigeminal plate. Case report. J Neurosurg 32: $367-370,1970$

18) Isaka $T$, Akai F, Kuroda $R$, Nakatani $S$, Taneda $M$ : [The quadrigeminal giant cyst communicating with lateral ventricle as a cause of obstructive hydrocephalus: a case report]. CI Kenkyu 17: 413-417, 1995 (Jpn)

19) Katagiri A: Arachnoid cyst of the cisterna ambiens. Report of two cases. Neurology (Minneap) 10: 783, 1960

20) Korosue K, Tamaki N, Fujiwara K, Matsumoto S: Arachnoid cyst of the fourth ventricle manifesting normal pressure hydrocephalus. Neurosurgery 12: 108-110, 1983

21) Kruyff E: Paracollicular plate cysts. AJR Am J Roentgenol 95: 899-916, 1965

22) Little JR, Gomez MR, MacCarty CS: Infratentorial arachnoid cysts. J Neurosurg 39: 380-386, 1973

23) Lourie H, Berne AS: Radiological and clinical features of an arachnoid cyst of the quadrigeminal cistern. J Neurol Neurosurg Psychiatry 24: 374-378, 1961

24) Miyagami M, Kasahara E, Miyazaki S, Tsubokawa T, Kagawa Y: [Ultrastructural findings of arachnoid cysts and epithelial cysts]. No To Shinkei 43: 545-553, 1991 (Jpn, with Eng abstract)

25) Odake G, Naruse S, Toyama M, Yamaki T: [Paracollicular cyst with choroid plexus-like epithelium (case report)]. No To Shinkei 25: 1829, 1973 (Jpn, with Eng abstract)

26) Ohtsuka $K$, Hashimoto $M$, Nakamura $Y$ : Bilateral trochlear nerve palsy with arachnoid cyst of the quadrigeminal cistern. Am J Ophthalmol 125: 268-270, 1998

27) Pagni CA, Canavero S, Vinci V: Left trochlear nerve palsy, unique symptom of an arachnoid cyst of the quadrigeminal plate. Case report. Acta Neurochir (Wien) 105: 147-149, 1990

28) Pascual-Castroviejo I, Roche MC, Martinez Bermejo A, Arcas J, Garcia Blazquez M: Primary intracranial arachnoidal cysts. A study of 67 childhood cases. Childs Nerv Syst 7: 257-263, 1991

29) Rengachary SS, Watanabe I: Ultrastructure and pathogenesis of intracranial arachnoid cysts. J Neuropathol Exp Neurol 40: 61-83, 1981

30) Ruge JR, Johnson RF, Bauer J: Burr hole neuroendoscopic fenestration of quadrigeminal cistern arachnoid cyst: technical case report. Neurosurgery 38: 830-837, 1996

31) Severinghouse JW, Mitchell RA: Ondine's cursefailure of respiratory center automaticity while asleep. Clin Res 10: 122, 1962

32) Shirakawa N, Mukai K, Fujisawa H, Furuichi S: [A case of intraventricular cyst associated with normal pressure hydrocephalic condition]. No Shinkei Geka 19: 897-902, 1991 (Jpn, with Eng abstract) 
33) Spaziante R, Cirillo S, Constans JP, de Divitiis E, Donzelli R, Stella L: Arachnoid cyst of the quadrigeminal cistern. Neurochirurgia (Stuttg) 29: 117-123, 1986

34) Starkman SP, Brown TC, Linell EA: Cerebral arachnoid cysts. J Neuropathol Exp Neurol 17: 484-500, 1958

35) Trowbridge WV, French JD: Benign arachnoid cysts of the posterior fossa. J Neurosurg 9: 398-404, 1952

36) Wakisaka S, Yoneda K, Kitano I, Kinoshita K, Matsuoka S: Arachnoid cyst in the quadrigeminal cistern. Surg Neurol 26: 52-58, 1986
37) Yanaka K, Enomoto T, Nose T, Maki Y: Post-inflammatory arachnoid cyst of the quadrigeminal cistern. Observation of development of the cyst. Childs Nerv Syst 4: 302-305, 1988

Address reprint requests to: C. Topsakal, M.D., Firat Üniversitesi, Tıp Fakültesi, Nörosirürji Departmanı, Elazı̆̆ 23100, Turkey.

e-mail:cdtopsakal@yahoo.com. 